\section{Importancia de las mutaciones del gen BRCA1 Y 2 en el cáncer de mama}

Importance of BRCA1 Y 2 gene mutations in breast cancer

Lisseth Alejandra Moreira Véliz

Md, Universidad de Guayaquil

lizzandra1991@hotmail.com;

https://orcid.org/0000-0002-6946-5880

Karen Rocío Peñaloza Carrión

Md, Hospital de Especialidades Teodoro

Maldonado Carbo, drakarenrociopc@gmail.com,

https://orcid.org/0000-0001-7284-3312

Guayaquil - Ecuador

http://www.jah-journal.com/index.php/jah

Journal of American health

Enero - Marzo vol. 4. Num. 1- 2021

Esta obra está bajo una Licencia Creative Commons

Atribución-NoComercial-CompartirIgual 4.0 Internacional.

RECIBIDO: 24. DE FEBRERO 2020

ACEPTADO: 18 DE DICIEMBRE 2020

PUBLICADO: 4 DE ENERO 2021
El objetivo de esta investigación es proporcionar una revisión actualizada de los conceptos más importantes de las mutaciones de los genes, BRCA1 gen del cáncer de mama 1 o BRCA2, gen del cáncer de mama 2 sin embargo, al existir una estrecha correlación con cáncer de ovarios dadas por estas mutaciones también abordaremos información general del cáncer de ovarios y se proporcionará las herramientas y claves diagnósticas para la identificación oportuna de la patología. Se realizó una búsqueda sistemática de investigaciones recientes en bases de datos de Elsevier, Pubmed y Scopus de artículos publicados en el idioma inglés y español. Se excluyeron ensayos clínicos, metaanálisis, reportes de casos y estudios de análisis de datos. Los BRCA1 se asocian con tipos más agresivo con peor pronóstico de cáncer por esta razón los cánceres de mama diagnosticados a temprana edad tienen la indicación de realizar una prueba genética, y los BRCA2 parecen tener menor relación heredofamiliar, aunque lo desarrollan a una edad más avanzada, sin embargo la prevalencia de las mutaciones BRCA1 y BRCA2 varía de acuerdo con el país y el grupo étnico, judíos asquenazí, de origen europeo y países como Islandia, Canadá, Polonia y Holanda que se han ido amplificando en las generaciones, contribuyendo a ello el aislamiento geográfico de la población.

PALABRAS CLAVE: BRCA1, BCRA2, cáncer de mama, importancia, factores

\section{ABSTRACT}

The objective of this research is to provide 
an updated review of the most important concepts of gene mutations, BRCA1 breast cancer gene 1 or $B R C A 2$, breast cancer gene 2 , however, since there is a close correlation with ovarian cancer Given by these mutations, we will also address general information about ovarian cancer and provide the tools and diagnostic keys for the timely identification of the pathology. A systematic search of recent research was carried out in Elsevier, Pubmed and Scopus databases of articles published in English and Spanish. Clinical trials, meta-analyzes, case reports, and data analysis studies were excluded. BRCA1s are associated with more aggressive types with a poorer prognosis of cancer, for this reason breast cancers diagnosed at an early age are indicated for genetic testing, and BRCA2s seem to have a less hereditary relationship, although they develop it at a later age However, the prevalence of BRCA1 and BRCA2 mutations varies according to the country and ethnic group, Ashkenazi Jews, of European origin and countries such as Iceland, Canada, Poland and the Netherlands that have been amplifying in the generations, contributing to this the geographic isolation of the population.

KEYWORDS: BRCA1, BCRA2, breast cancer, importance, factors

\section{INTRODUCCIÓN}

La mayor parte de los casos hereditarios de cáncer de mama (CM) están relacionados con dos genes que presentan anomalías: gen del cáncer de mama 1, (BRCA1) o gen del cáncer de mama 2 (BRCA2). Las mujeres con esta mutación tienen mayor riesgo de desarrollar cáncer de mama y también cáncer de ovario (1). De hecho, el Instituto Nacional del Cáncer, señala que las mujeres con esta alteración presentan el $60 \%$ de riesgo que le diagnostiquen cáncer de mama en el transcurso de su vida (1) y para el cáncer de ovario el gen BRCA1 el riesgo es de alrededor de $40 \%$, y el riesgo de una portadora BRCA2 es de $20 \%$, aunque lo desarrollan a una edad más avanzada (2).

Según estudios señalan que alrededor del $12 \%$ de las mujeres de la población en general padecerán cáncer $\mathrm{CM}$ alguna vez en sus vidas. Por el contrario, un reciente estudio grande calculó que 72 \% de las mujeres que heredan una mutación en el BRCA1 y cerca de $69 \%$ de las mujeres que heredan una mutación en el BRCA2 presentarán cáncer de seno para los 80 años de edad (3).

Además de estos tipos de cáncer también se han registrado otras asociadas de canceres en edades más jóvenes que las personas que no tienen estas mutaciones (3). Existen cinco subtipos diferentes de tumores: luminal A, luminal B, tipo mamario normal, sobre expresión HER2 y tipo basal, los cuales presentan diferentes comportamientos biológicos. El subtipo basal se asocia con mal pronóstico y es observado en 80 a $90 \%$ en las portadoras de mutaciones BRCA1 (2). 
Una "mutación", sea en BRCA1 o en BRCA2, implica para la mujer un aumento del riesgo de desarrollar cáncer de mama y ovario y en los hombres también tienen un mayor riesgo de desarrollar cáncer de mama y de próstata. Además existe un leve aumento en el riesgo de desarrollar otros tipos de cáncer, incluidos cáncer de páncreas y melanoma, en personas con mutaciones en BRCA1 o BRCA2 (4).

Entre los factores de riesgos de (CM) encontramos la historia familiar positiva, os genes BRCA1 y BRCA2 y actualmente también se ha observado el gen BRCA3 según Seitz, 2017. No obstante, estas mutaciones en estos, no explican todos los CM familiares, por ende, es posible que existan otros genes de baja penetrancia para CM por conocer e identificar (5).

El objetivo de esta investigación es proporcionar una revisión actualizada de los conceptos más importantes de las mutaciones de estos los genes, (BRCA1) gen del cáncer de mama 1 o gen del cáncer de mama 2 (BRCA2), sin embargo, al existir una correlación con cáncer de ovarios por estas mutaciones también abordaremos información general del cáncer de ovario.

\section{MATERIALES Y MÉTODOS}

Se realizó una búsqueda bibliográfica en PubMed y Scielo, Scopus de los últimos 5 años previos a esta publicación. Se incluyeron estudios de revisión narrativa o sistemática sobre conceptos más importantes de las mutaciones de estos los genes, (BRCA1) gen del cáncer de mama 10 gen del cáncer de mama 2 (BRCA2), además del cáncer de ovario por su asociación a estas mutaciones, que fueron redactados en idioma inglés o español mediante palabras claves "BRCA1", "BCRA2, "cáncer de mama", "importancia,", "factores". Se excluyeron los artículos sobre cartas a los editor y memorias de congresos. Se proyectó un total de 50 artículos, de los cuales se seleccionaron 19 investigaciones completas de los ultimas publicaciones y otras relevantes para el desarrollo de este trabajo.

\section{RESULTADOS}

Estudios iniciales estimaron un riesgo del $87 \%$ de desarrollar CM las asociadas a gen BRCA1 y 40-60\% cáncer ovarios, sin embargo, en estudios realizados por Struewing y cols. en mujeres y hombres judíos, el riesgo de desarrollar CM fue del 56\%, cáncer de ovario $16 \%$ y cáncer de próstata 16, el sesgo que tuvieron los primeros estudios, fue de selección de las familias con mayor número de casos tanto de CM como de ovario y con mayor cantidad de mujeres jóvenes.

Las hijas de portadoras tienen un riesgo del $50 \%$ de heredar el gen mutante y por lo tanto de desarrollar CM o cáncer de ovario (5), de todas maneras, la prevalencia de las mutaciones BRCA1 y BRCA2 varía de acuerdo con el país y el grupo étnico, por ejemplo, los ancestros judíos asquenazí, de origen europeo y países como Islandia, Canadá, Polonia y Holanda. Prevalencia debido a la presencia de mutaciones fundadoras, que se han ido amplificando en las generaciones, contribuyendo a ello el aislamiento geográfico de la población (6). 
La mutación del gen BRCA 2, explica el $40 \%$ de los cánceres de mama hereditarios. El riesgo es de $7 \%$ para el cáncer mamario masculino, $8 \%$ para el cáncer de próstata, además, presenta una asociación con los carcinomas de páncreas, cabeza y cuello, colon, esófago, pulmón, tumores hematopoyéticos y el melanoma maligno (7).

En las mujeres portadoras de mutaciones en el gen, el riesgo acumulado hasta los 70 años se estima entre 50 y $95 \%$ para cáncer de mama. El varón portador de la mutación BRCA1 tienen un $1 \%$ de riesgo aproximado para desarrollar cáncer de mama (6).

\section{Opciones terapéuticas:}

La vigilancia de las portadoras BRCA incluye un autoexamen mensual de la mama a partir de 25 años, examen clínico de la mama bianual, mamografías anuales o bianuales desde los 25-35 años; resonancia magnética en conjunto con la mamografía de ser posible aumentando la sensibilidad y especificidad hasta en $95 \%$. (2)

La investigación familiar positiva tiene un riesgo relativo (RR) es de 2 para una mujer cuya madre o hermana fue diagnosticada con $\mathrm{CM}, 10$ para los familiares de primer grado cuando el $\mathrm{CM}$ se presenta en etapa premenopáusica y es bilateral y hasta 150 para una mujer de 40 años portadora de una mutación en el gen BRCA1, por ende, estos datos son (5) por lo tanto las pruebas genéticas son mandatoias; de hecho, en técnicas de reproducción asistida en estudios realizados el $78 \%$ y el $64 \%$ de los individuos opinaba que era ético ofrecer diagnóstico prenatal y diagnóstico preimplantacional, respectivamente, en individuos portadores de una mutación en $B R C A 1 / 2$ (8)

La estimación de la penetrancia de mutaciones de BRCA detectadas en series de casos de CM y ovario no seleccionados por la historia familiar ofrece resultados menos dramáticos, pues, según estudios, sin numerosos antecedentes familiares, se sabe que la presencia de portadores de una mutación y diagnosticados de cáncer de mama a edades tempranas (menores de 35 años) supone un incremento en el riesgo acumulado para cáncer de mama en portadores de BRCA1 y para cáncer de ovario en portadores de BRCA2 que se sitúa en el rango de las cifras publicadas por el BCLC en familias de alto riesgo (9).

Estudios de las predisposiciones hereditarias al cáncer mamario asociadas a BRCA1/2, han determinado de mutaciones germinales de los genes BRCA mediante la combinación del test de la proteína truncada (PTT) y el análisis de heterodúplex (HDA), seguido de la secuenciación directa de los productos de PCR con bandas variantes anormales. Debe incluir asesoramiento genético a las familias Debido al elevado costo e insumo de tiempo de las técnicas utilizadas, por esta razón podría existir limitaciones y discontinuar la marcha el estudio de estos genes mediante secuenciado masivo de ADN, en el marco de la cooperación con el Instituto Pasteur de Montevideo y manteniendo el asesoramiento previo y posterior a la realización de los test genéticos (10).

El respaldo psicológico a la persona y la obtención de un diagnóstico más confiable; que a largo plazo reducirían los costos del cáncer sobre todo en países en vías de desarrollo estas pruebas 
no están ampliamente disponibles. No obstante, en países desarrollados la secuenciación de ADN hace parte del abordaje clínico de los pacientes potencialmente en riesgo de CM hereditario, situación beneficiada por la rápida disminución de los costos de secuenciación de ADN (11).

La nueva clase de medicamentos que se está estudiando en portadores de BRCA1/2 se conoce como inhibidores de la PARP, estudiados en personas con tumores avanzados relacionados con mutaciones del BRCA1/2 heredadas y las no relacionadas. En mujeres y hombres en estos ensayos, resulto reducción del tamaño del tumor, y en muchas otras. Por lo tanto, se debe seguir explorando estos medicamentos. Los inhibidores de la PARP también han sido (12).

Las opciones quirúrgicas para estas pacientes son la cirugía extensa (mastectomía bilateral), para prevenir un cáncer secundario o un cáncer de mama contralateral. Se ha estimado que el riesgo en portadoras del BRCA1 de padecer cáncer de ovario después de 10 años de haber sido diagnosticado el cáncer de mama es de $13 \%$ (2).

\section{DISCUSIÓN}

Los cánceres asociados con mutaciones BRCA1, se asocian con tipos más agresivo con peor pronóstico se tratan de canceres ductales infiltrantes, de tipo basal, con un alto grado histológico, con características medulares, infiltración linfocitaria, patrón de crecimiento sincicial y resultan ser triple-negativos (2).

En general, ambos el BRCA1 y BRCA2, tienen valores de penetrancia que oscilan alrededor de $80 \%$ (2). Por lo tanto, es una herramienta útil en el caso de cáncer de mama. Una vez determinada la presencia de alguna mutación en una familia, es posible identificar a los miembros portadores de dicha mutación mediante el diagnóstico molecular presintomático (8). La biología molecular y la aparición de las pruebas genéticas en los procesos oncológicos, ha permitido desarrollar técnicas que permiten la identificación de las principales mutaciones encontradas en los genes BRCA, fundamentadas en la reacción de la cadena de la polimerasa (PCR) y la secuenciación del ADN (6).

Ciertas variaciones del gen BRCA2 pueden causar un incremento del riesgo de sufrir cáncer de mama, como las inserciones o deleciones de un pequeño número de pares de bases de ADN en el gen, por lo cual la proteína codificada BRCA2 es anormal y no funciona correctamente (6). Es sabido ya que se heredan mediante un patrón autosómico dominante, situados en los cromosomas BRCA1 (17) Y BRCA2 (13), respectivamente, y es suficiente heredar un único alelo para tener un riesgo aumentado de cáncer (13) (14).

Las mutaciones en el residuo S404 de abraxas, así como dos mutaciones en BRCA1, producen pérdida de función de BRCA1, y por ello aumentan las probabilidades de que el daño en el ADN no pueda ser reparado. (13), Se ha demostrado que BRCA1 forma parte del multicomplejo que incluye a las proteínas básicas para reparación como MSH2, MSH6, MLH1, ATM y BLM. Este complejo funciona como censor para daño al DNA. BRCA1 además es capaz de interaccionar con la proteína p53 en sitios múltiples estimulando así la actividad transcripcional de esta 
proteína (15). Actualmente, se sabe que debido a las mutaciones que afectan al gen, la proteína BRCA1 no entra al núcleo, permaneciendo en el citoplasma de la célula (16).

Por supuesto que no siempre la mutación fundadora identifica las pacientes de alto riesgo; existen excepciones como, por ejemplo, el caso de una mujer que tenga una historia familiar significativa de cáncer de mama y el resultado de la prueba para la mutación fundadora sea negativo. En este caso, es necesario proseguir con la realización de una prueba de secuenciamiento completo (2).

El cáncer de mama esporádico, el cáncer de mama familiar negativo para mutaciones en BRCA1 o BRCA2 y el cáncer asociado a portadoras de mutaciones BRCA1 y BRCA2 se diferencian en la morfología, en el fenotipo inmuno-histoquímico y en las características moleculares. De manera general, el $90 \%$ de tumores de mutaciones en BRCA1 presenta receptores de estrógenos y progesterona y HER2 negativo, sin embargo, aún no se conoce la proporción de tumores de receptores negativos que poseen mutaciones en BRCA1, al contrario que los de BRCA1, los BRCA2 son positivos para receptores de estrógeno y progesterona, asemejándose a los tumores de cánceres no hereditarios (17), es decir no se diferencian de los tumores de cánceres esporádicos (18) (4).

La mayor parte de los casos de cáncer de mama ocurren al azar, de causa desconocida, por lo que someterse a pruebas de detección de mutaciones en el gen $B R C A 1$ o $B R C A 2$ podría no ser útil para la mujer promedio. Las recomendaciones genéticas se dan principalmente para personas que tienen antecedentes personales y/o familiares. No obstante, en menores de 60 con cáncer de mama triple negativo corren el riesgo de tener una mutación en $B R C A$, independientemente de los antecedentes familiares.

Los portadores de esta alteración genética tienen un riesgo mayor que la población general de desarrollar cáncer de mama (60-70\% a lo largo de la vida) y cáncer de ovario (20-40\% a lo largo de la vida) principalmente. Otros tumores asociados al síndrome son cáncer de próstata, cáncer de páncreas, melanoma. Cada hijo de una persona portadora de mutaciones en BRCA 1 y 2 tiene el 50\% de probabilidad de heredar la alteración genética, y 50\% de no heredar (19), (4).

Como se ha mencionado el desarrollo de cáncer de mama puede estar influenciado por factores ambientales y genes modificadores, aún no determinados. Por lo tanto, conocer las peculiaridades que presentan las familias de alto riesgo permitirá identificar la predisposición de desarrollar cáncer de mama y, recomendar el asesoramiento genético que aportará un beneficio en cuanto a la educación y determinación del riesgo, aminorando el impacto psicoemocional (18).

Por esta razón los cánceres de mama que se deben diagnosticar a temprana edad, con indicación de una prueba genética, mientras que los relacionados al BRCA2 parecen no diferir de los cánceres de origen no hereditario (2). 
Todas estas acciones ayudasen a identificar mutaciones en BRCA1/2 para implementar intervenciones médicas tempranas y mejorar el conocimiento sobre el cáncer hereditario de mama y predecir la presencia o no de una mutación BRCA y seleccionar el tratamiento óptimo para una mujer afectada (18).

\section{CONCLUSIONES}

El desarrollo de cáncer de mama puede estar influenciado por factores ambientales y genes modificadores, sin embargo, las mutaciones en los genes BRCA1 y BRCA2, aumentan la probabilidad de padecer cáncer de mama en $60 \%$ a $85 \%$. En la actualidad, se estima que menos del $1 \%$ de la población general tiene una mutación en los genes BRCA1 o BRCA2, y hasta un $10 \%$ de las mujeres y un $20 \%$ de los hombres con diagnóstico de cáncer de mama presentan una mutación en uno de estos genes. El 90\% de tumores de mutaciones en BRCA1 presenta receptores de estrógenos y progesterona y HER2 negativo, los BRCA2 son positivos para estos receptores asemejándose a los tumores de cánceres no hereditarios. Sin embargo, también pueden existir otras mutaciones en otros genes relacionados con el riesgo de cáncer de mama. Por ende, se recomienda que las mujeres con cáncer de mama triple negativo reciban asesoría genética y se realicen pruebas genéticas. Conocer las peculiaridades que presentan las familias de alto riesgo permitirá identificar la predisposición de desarrollar cáncer de mama y, recomendar el asesoramiento genético que aportará un beneficio en cuanto a la educación y determinación del riesgo, aminorando el impacto psico-emocional, diagnosticar a temprana edad es una opción en países desarrollados, lo que no implica que a largo plazo pueda darse en países de vías de desarrollo.

\section{Referencias}

1. Breastcancer.org. Análisis de BRCA1 y BRCA2. [Online].; 2016. Available from: https://www.breastcancer.org/es/sintomas/diagnostico/brca.

2. Norad SA, Rodríguez AA. Predisposición genética para el cáncer. Salud pública de méxico vol.53. 2011.

3. Instituto Nacional del Cáncer. Mutaciones en BRCA: Riesgo de cáncer y pruebas genéticas. [Online].; 2018. Available from: https://www.cancer.gov/espanol/cancer/causasprevencion/genetica/hoja-informativa-brca.

4. Cancer.Net JEd. Cancer.net. [Online].; 2019. Available from: https://www.cancer.net/es/tipos-dec\%C3\%A1ncer/c\%C3\%A1ncer-hereditario-de-mama-y-de-ovario.

5. Almeida Barba K, Castillo González AM, Fuertes Arévalo RA, Rodríguez Becerra DF. Cáncer de mama ligado al gen BRCA1. RECIAMUC. 2020;: p. 100-113.

6. Fernández T. Á, Reigosa Y. A. CÁNCER DE MAMA HEREDITARIO. Comunidad y Salud vol.14 no.1. 2016. 
7. Calderón del Valle SA, Gallón Villegas J. Cáncer de mama asociado a. Revista CES MEDICINA Volumen 26 No. 2. 2012.

8. UABDivulga. UABDivulga Barcelona Investigación e Innovación. [Online].; 2009. Available from: https://www.uab.cat/web/detalle-noticia/implicaciones-eticas-de-los-genes-em-brca1/2-/em1345680342040.html?articleld=1243578582010.

9. Seom.org. SEOM. [Online]. Available from: https://seom.org/seomcms/images/stories/recursos/sociosyprofs/documentacion/manuales/can Her/mama.pdf.

10 Delgado Pebé L. Universidad de la República de Uruguay. [Online]. Available from: . http://www.universidad.edu.uy/renderResource/index/resourceld/27827/siteld/1.

11 Orozco Hernández JP, Marín Medina DS, Martínez Muñoz MA, Martínez JW. Genes de . predisposición al cáncer de mama. Revista Salud Uninorte, vol. 34, núm. 3. 2018.

12 BRCA. Basser Center for BRCA. [Online]. Available from:

. https://www.basser.org/espanol/tratamiento-de-tipos-de-cancer-relacionados-con-el-brca.

13 Álvarez Gama J. UNIVERSIDAD DE CANTABRIA. [Online].; 2016. Available from: . http://hdl.handle.net/10261/164963.

14 Sanabria MC, Muñoz G, Vargas $\mathrm{Cl}$. Análisis de las mutaciones más frecuentes del gen . BRCA1(185delAG y 5382insC) en mujeres con cáncer de mama en Bucaramanga, Colombia. Biomedica Vol. 29 Núm. 1. 2009.

15 Vidal Millán S. Cáncer de Mama Hereditario: Identificación y Elección de Pacientes para Estudio . Molecular de los Genes BRCA. Instituto Nacional de Cancerología. Cancerología 3. 2008;: p. 51-61.

16 Mora E, Villegas J, Solorzano Z, Reigosa A. Expresión de BRCA1 en mujeres con neoplasias . epiteliales de ovario del Estado Carabobo, Venezuela. Revista Venezolana de Oncología, vol. 29, núm. 2. 2017.

17 González Teshima LY, Vargas Cely FS, Muñoz Sandoval JS, Ramírez Cheyne J, Saldarriaga Gil W. . SÍNDROME DE CÁNCER HEREDITARIO DE. Revista Colombiana de Obstetricia y Ginecología Vol. 67 No. 1. 2016.

18 Margarit S. CÁNCER HEREDITARIO DE MAMA. Rev. chil. radiol. v.14 n.3. 2006;: p. 135-141.

19 Hospital Italiano de Buenos Aire. Hospital Italiano de Buenos Aire. [Online]. Available from: . https://www1.hospitalitaliano.org.ar/\#!/home/procanhe/seccion/35292. 
